\title{
Corporate Lifecycles: Modelling the Dynamics of Innovation and Its Support Infrastructure
}

\author{
Tamas Koplyay, Lisa Chillingworth, and Brian Mitchell
}

\author{
"Concentrate your energies, your thoughts, and your") \\ capital. The wise man puts all his eggs in one \\ basket and watches the basket.
}

\author{
Andrew Carnegie \\ Business magnate and philanthropist
}

\begin{abstract}
Corporate leadership and corporate culture have to be aligned to market realities to ensure the long-term success of a firm. As companies form, grow, and mature, the management of the enterprises also have to evolve through the business lifecycle. What is successful in the introduction stage may not be successful for a mature company. Firms are required to change their focus from product development, to market development, to process development, and finally to market and financial leadership. To be successful means that not only the types of employees hired have to evolve to support the culture required, but the leadership styles and management focus also have to change and adapt to the new realities that firms encounter in their market. The dynamic model presented in this article shows the broad strategic imperatives that must be met by firms, and it is presented through a graphical illustration of how successful firms manage their evolution and how firms can fail through mis-allocation of corporate efforts to non-mission critical initiatives.
\end{abstract}

\section{Introduction}

Although the effects of leadership and culture on innovation are well known, and various factors that influence innovation have been examined extensively in literature, a consistent model explaining the relationships between leadership, culture, and innovation is lacking. Additionally, the characteristics of the evolutionary change throughout the corporate lifecycle and the constituent individual phases delivering the innovation are poorly understood.

At the core of this article is a model that incorporates the effect of leadership and organizational culture upon the evolution of innovation during the firm's market lifecycle. The model is predictive and explanatory, and it incorporates the changing profiles of culture and leadership as well as some critical staffing issues. The article presents the foundational aspects of the model that treats the factors as a dynamic ensemble and aligns cul- ture, leadership, and corporate function with the type of innovation being pursued. The organizing framework of the market lifecycle is the foundation upon which this model is built, but the concurrent phenomena of product and the firm lifecycles will also be considered.

The ideas presented in this article are the culmination of the primary's author's 20 years of experience teaching, consulting, and acting in director-level research roles in the high-technology industry. Many of these concepts are derived from the lifecycle theory extended by the author and have been tested in over 200 case studies, industry surveys, and consulting assignments.

\section{The Dynamic Duo: Culture and Leadership}

Like people, organizations develop and live within a culture and respond to specific leadership. However, as opposed to the individual, organizations pass through 


\section{Corporate Lifecycles: Modelling the Dynamics of Innovation and Its Support Infrastructure} Tamas Koplyay, Lisa Chillingworth, and Brian Mitchell

several stages of development of culture and experience different leadership styles depending upon where they are in their own product, market, and firm-maturity lifecycles.

A startup generally is led by a focused entrepreneur who, through almost messianic leadership, focuses the firm on the potential of the future and can be nimble in management decisions and changes in strategic direction. With the focus on potential success, creativity and innovation are generally nurtured and promoted during the initial stages of the technology lifecycle (tinyurl.com/6cog6u). Should the firm enjoy the market's early adopters becoming their clients, the firm can focus on attracting the early and late majorities of the market customers. Moore's (2005; tinyurl.com/lzstrav) work on market cycles can be used to show that once the early majority is engaged, the firm has moved from an introductory stage to a stage that is characterized by growth. Through the introduction and early growth stages, management of the firm is dynamic and fluid. Trial and error can create small failures that evolve into long successes over time.

However, in the case of market entry by firms whose cultures are not aligned with the early market, problems can ensue. As cultures supersede each other along the lifecycle, as will be later explored in this article, product creativity becomes progressively restrained and even stifled within the firm, and the competitive edge for young markets is effectively lost for the marginal and incremental innovation that accompanies a mature or declining market. The entanglement gets even worse when the three cycles of product, firm, and market interact.

An example of a culture clash between market lifecycle position and management is highlighted in the following example from the Canadian high-technology industry. A mature firm may try to enter a startup market with growth products by spinning off a division or a wholly-owned company, as was the case with Entrust (entrust.com), a pure startup in internet security. In 1994, Entrust was born of Nortel (tinyurl.com/24gm7a), a mature telecommunications networking company, and was competing with products that perhaps were more suitable for a growth market than the startup situation. There was a triple incompatibility between: i) the firm's startup culture, ii) its large parent's culture, and iii) its products, which it intended to bring to market as complements to other firms' products. This triple incompatibility of market, firm-management culture, and product lifecycles leads to a strategic gap that can be impossible to manage. Only once free of the parental embrace, was Entrust able to quickly adjust its strategic focus to create long-term market traction, and it continues to be relatively successful at the time of writing this article in 2013.

As a further example of such a management challenge, consider a company that competes with a product portfolio that ranges from startup to mature, and offers these products through affiliates into markets of differing stages of development, hence of different cultural profiles. Such was the case with another Canadian hightechnology company, Newbridge Networks (tinyurl.com/ lma83fl). At its maturing stage, several young startups controlled by Newbridge pursued their own market ambitions and were barely linked to the parent through minimal ties of administrative and financial support. The reason for this was primarily to prevent the submerging and capture of the young firms' cultures by the dominant, mature culture of the parent. The young firms remained in orbit around the parent but never came close enough to be captured by the inexorable gravitational pull of the parent's culture. Similarly, when Research In Motion (now BlackBerry: black berry.com) acquired QNX (qnx.com), a strategic distance was maintained to allow QNX to breathe in its own rarified entrepreneurial atmosphere. Such efforts underscore the importance of keeping a young culture at an arm's length from a mature one, because the mature culture eventually contaminates and destroys the inherent creativity of the younger firm. There is a hierarchy of dominance, especially in the high-technology sector, where maturity dominates growth and growth dominates startups.

How does a startup culture transform into a growth culture and why? The rules of the game change markedly when, and if, the bridge is crossed from early market to mass market, especially with high growth. Management now has to deal with early majority customers and selecting the correct target customers. Additionally, customers become more price conscious, thereby driving margins downward. Product feature development give way to reliability and compatibility concerns. During this time, the leadership and culture have to adjust from free-form innovation to more risk aversion and customer focus. Developers give way to functional managers, and the entrepreneur gives way to professional managers. Part of this process can also be explained by the needs of the venture capital investors who are looking for returns at the earliest time. Sales 


\section{Corporate Lifecycles: Modelling the Dynamics of Innovation and Its Support Infrastructure} Tamas Koplyay, Lisa Chillingworth, and Brian Mitchell

and distribution channels now matter as much as the product itself, and management adjusts again to a different frame of perception. The growth firm expansion can move toward the lean manufacturing model popularized in Japan where innovation is incremental (Koplyay et al., 2009; tinyurl.com/k98wndr) and not able to deal with sudden market or technological changes such as disruptive technologies (Christensen, 1997; tinyurl.com/ 7onvohk).

Once the high-growth period levels off and maturity is reached, the firm becomes more entrenched in the professional management of internal resources, profit margins, and distribution channels in order to make efficient production and sales choices. At this early maturity stage, the firm invests in both soft infrastructure (e.g., marketing channels, supply chain management, and training programs) and hard infrastructure (e.g., technology and production capacity, if not outsourced). The investments are focused on maintaining or increasing market share. Much of the managing is now focused on protecting the shareholder's equity and building or maintaining the stock price, or maximizing private ownership's return on investment. The customer base now contains the late majority, where customer skepticism, product functionality, and pricemotivated consumer behaviour drive the firm's management decisions. Price leadership, thus commoditizing the outputs and creating local price inelasticities through minimal product differentiation within the market space, is the focus of management. Production efficiencies become critical in a commoditized and competitive market (Kim and Mauborgne, 2005; tinyurl.com/l7g2kzg) and market share is either won through price leadership or growth through mergers and acquisitions. These approaches dominate strategic thinking in order to create better economies of scale and underpin a successful cost-leadership strategy in a price-taker market.

To accommodate this new reality, the culture/leadership scene transforms again with a mature, top-down approach with much formalized structures through rules, regulations, and policies, all of which are reinforced through training and careful cultivation of corporate culture benchmarks. The mature market is fairly predictable, both in terms of customer conduct and competitor behaviour, so much so that planning can become routine if somewhat circumspect and data rich, and some of the surprise moves of the occasional cunning competitor can be discerned through competitive intelligence. So, if the market lacks true dynamics, and everyone is running with the same cost-leadership strategy then it is inside the firm that competitive advantage must be gained. And, in fact, that is exactly what happens: the emphasis is on strategy implementation and not choice, unless a firm such as Apple decides to create a niche market and then later reinvades the mass market from this market niche refuge. As the market ossifies, so does the specific firm culture, and it becomes entirely devoid of bold imagination and obsessively focuses on production, incremental innovation, cash flow management, and efficiency. There is one more potential transition from a quality culture to a production culture, where discipline becomes the operating maxim, the timing of market exit becomes critical, and redeployment of cash flows dominate.

\section{Culture and Leadership Follows Lifecycle}

The organizational lifecycle, as defined by Rowe and colleagues (1993; tinyurl.com/l29nhee), divides the firm's evolution into four stages: Introduction, Growth, Maturity, and Decline. In each stage, a different type of leadership and organizational culture is required for success. During the Introduction stage, the leadership style is generally inspirational with a creative organizational culture. Growth requires both supportive leadership and organizational culture as the firm begins to develop its unique culture and organizational standards. During this time, transformational leadership of "motivation, empowerment, and morality" is required, as defined by Gill (2011; tinyurl.com/ldmg8aa). As the firm moves into Maturity, the dynamics change: leadership becomes more logical and formal, the culture moves towards a quality focus and becomes incremental concerning innovation. During the Decline stage, the production and cost-focused culture is driven by a directive and oftentimes remote leadership style. Notwithstanding Gill's assertion that transformational leadership should be pursued throughout the life cycle, the latter two stages tend to evolve into transactional management/leadership and generally are based upon the reward/penalty power of management.

It is important to note that a precise match must remain between culture and its corresponding leadership. At the turn of the century, Ford Motor Company ran into a major crisis, when its leader, Jacques Nasser, insisted on rejuvenating its culture by shifting focus from their core competency of automobile design and manufacturing to a broadly-based conglomerate by acquiring automobile junk yards and auto repair shops in Europe (Rothschild et al., 2004; tinyurl.com/kqroqtc), and providing a personal computer for most employees (Langer, 2003; tinyurl.com/ltxmov5). This effort to instill 


\section{Corporate Lifecycles: Modelling the Dynamics of Innovation and Its Support Infrastructure} Tamas Koplyay, Lisa Chillingworth, and Brian Mitchell

more creativity through the disruption of existing routines caused immense confusion, resulting in collapsing operating and financial fortunes and led to the hasty departure of Nasser from Ford. On the other hand, transformational leadership at IBM by the CEO Lou Gerstner became a spectacular success. The transformation at IBM was done in a very different way than Nasser's attempt at changing Ford's corporate culture. Gerstner first parceled out the company into independent units and then endowed each with its own appropriate culture and leadership depending on the markets served (Gerstner, 2003; tinyurl.com/kzogngf). There was no cultural overlap or dissonance as there was at Ford. In light of these examples, several important points should be made about the dynamics of culture and leadership. First, culture is path-dependent. How you get there matters, whether culture arises naturally and was nurtured, as is commonly the case in startups, or is imposed by necessity, as in IBM. A young culture has no antecedent and forms largely due to the staffing policies of the firm, by the hiring of young, ambitious, and dream-fuelled product developers who have the same background and temperament. This condition reinforces the young culture because it prevents the formation of silos, and the culture is easily diffused throughout the organization and maintained within it. Furthermore, incentives, such as stock options, create a natural driver that propels everyone in the same direction for the young culture to strive to build firm success that they will benefit from once the firm transitions from startup to growth.

Mature company cultures have a lot of stability with formal structures and defined hierarchies, whereas startup cultures are fragile: remove the messianic entrepreneurial leader and stock options, and introduce diversity of individual backgrounds into hiring, and this culture will disintegrate fairly quickly. Normally, when leadership and culture are in conflict, it is leadership that loses, as in the case of Jacques Nasser at Ford. The exception of IBM represented a conscious effort to destroy and rebuild the culture by a secure and determined leader who was ready to risk the future of the firm by doing several cultural reversals and transplants.

\section{Staffing Influences Culture and Follows Lifecycle}

Concurrent with the transitions of culture and leadership within the firm travelling through the corporate lifecycle, staffing challenges follow suit and succeed in orderly fashion to match the evolutionary changes. Again, incompatibility can lead to either sub-optimal performance, dysfunction, or long-term employee dissatisfaction. In young cultures, we find self-motivating, risk-taking, and team-oriented players who totally invest their efforts in the long-term success of the firm. As culture progresses to the Growth stage, where more formal structures tend to become risk averse, the risk taking is washed out and teams become silo-prone functional groups, and compensation focuses more on individual performance than the collective results. This change occurs largely because tasks are much better defined in the mature firm and are narrower in scope, and hence compensation can be tailored to the task or responsibilities at hand. But, there are obvious drawbacks given that the commonality of purpose may be lost. Workers, whose job is to produce a set product in a lean manufacturing environment, will continue to do so until they are told to change; their positions do not allow them to know or understand the corporate strategy and the efficacy of such strategy. Workers on the production floor have their performance measured in short timespans, whereas the performance of the senior executives are measured in a time horizon of months or years depending on the marketing and production cycles of the firm. Dysfunction can creep into the firm as employees producing the product are performing their jobs in a stellar fashion, yet the product itself is not being purchased by consumers; thus, the production staff are not contributing to the ultimate success of the firm, no matter the quality of their efforts.

As the firm evolves through the lifecycle, the actual types of people employed by the firm can also impact the success of the firm. As with management, the fit of the employee grouping can have a positive or negative impact on the firm's productivity and profitability. During the Introduction stage, small startup companies tend to "make do" with the resources they have; generalists are in high demand. Those who are willing to take risks and able to react to sudden changes are generally also those who are willing to forego high wages by building stock ownership as a form of compensation. As the firm enters Growth, the types of employees become more risk averse and fit into functional groupings with increased organizational discipline. As Maturity is reached, the formal structure of the firm requires employees who have highly differentiated roles and responsibilities, fit into the established corporate routines, and can be nominally proactive. Decline tends to exhibit a highly regimented structure with employees focused on the process and cost containment, a high degree of labour specialization, and risk aversion as an individual and corporate trait. 


\section{Corporate Lifecycles: Modelling the Dynamics of Innovation and Its Support Infrastructure Tamas Koplyay, Lisa Chillingworth, and Brian Mitchell}

\section{Managing the Dimensions of Innovation}

Management of innovation requires a wide spectrum of approaches with different levels of interventions through the firm's lifecycle. The four factors that we have identified are what we consider to be the dominating dimensions of innovation that have to be managed through the corporate lifecycle:

\section{Product Innovation: research and development}

2. Marketing Innovation: channel building

3. Process Innovation: production and logistics

4. Financial Innovation: funding of growth and reinvesting surplus capital

These dimensions are not managed without regard to other business imperatives, but they are the most important for the lifecycle phase the firm is in. Figure 1 shows the egg shape formed by the dimensions of innovation management. The oblong shape illustrates that, depending upon the lifecycle phase the firm is presently in, certain dimensions are more important than others; although the other dimensions still have to be considered, the imperative management focus for the lifecycle phase thus requires a greater proportion of management's attention.
In Figure 1, the "equilibrium" state is shown to indicate the four dimensions of innovation management and the quadrant orientation, but this state is never a reality in the firm's business-management conditions. One dominating dimension needs to be managed with more time, resources, and care to be successful in each stage of the business lifecycle. The curved arrows within each "egg" also show the direction of the management evolution: from product innovation to marketing innovation, to process innovation, and finally to financial innovation. The dotted arrows show the potential for the rebirth of the firm after the Decline stage, but the reality is that the firm either reinvents itself or is liquidated and closed.

In the Introduction stage, focus on product innovation management is the prime concern. As the firm transitions in the lifecycle from the Introduction to the Growth stage, the management focus also has to evolve. This shift is not instantaneous, but will take varying spans of time to complete. Once fully transitioned, as shown in Figure 1, the management focus can be rightly applied to the market imperatives for the success of the firm in the lifecycle stage they find themselves in. As the firm evolves to the Growth stage, management continues to focus on the product itself, with less emphasis on innovation as the product adapts to the existing channels. Market uptake can lead to Moore's "tornado" (2005; tinyurl.com/lzstrav), where the

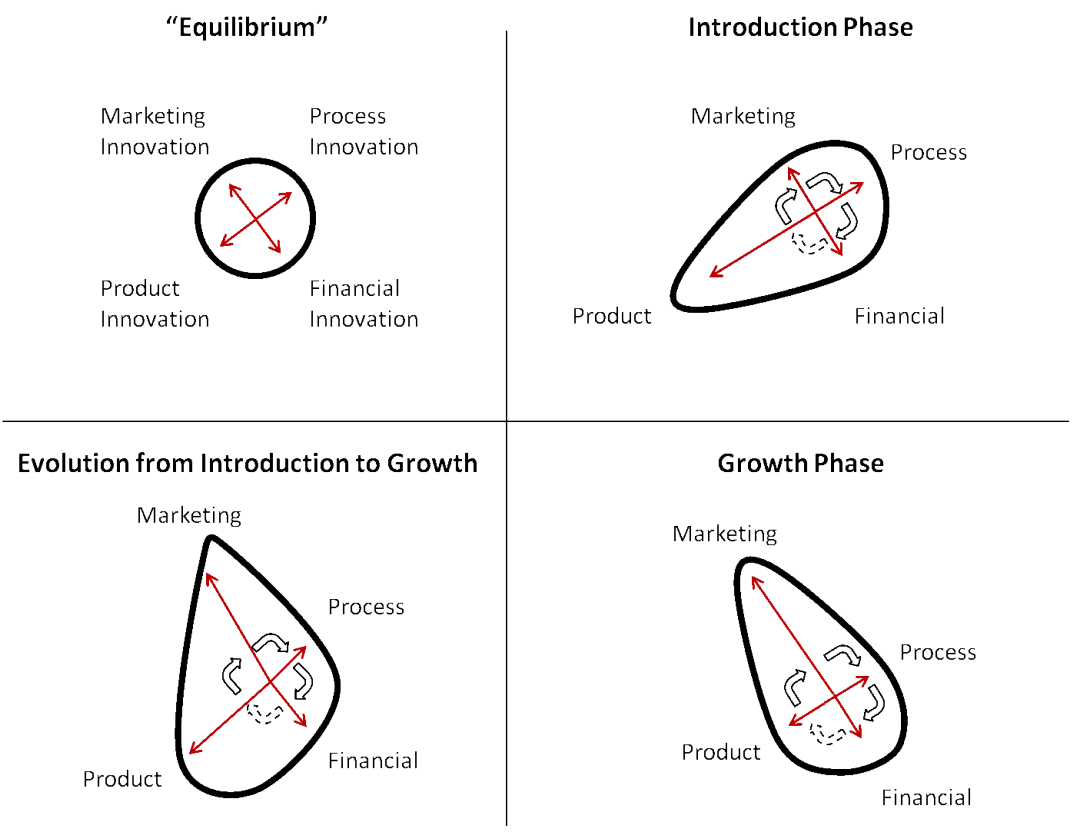

Figure 1. The dimensions of innovation and the evolution of management's "egg-shaped" focus through a firm's lifecycle 


\section{Corporate Lifecycles: Modelling the Dynamics of Innovation and Its Support Infrastructure Tamas Koplyay, Lisa Chillingworth, and Brian Mitchell}

product suddenly gains traction in the marketplace, and increases in demand lead to mass marketing, meeting production targets, and pursuing market segmentation.

The "egg" or oblong shape plays an important role in what happens to the firm in the market space. The concept of the egg shape is analogous to how management has to make decisions in the lifecycle. The oblong shape allows for the forward motion by transferring the motion "up" and providing momentum to the next stage. When moving from a focus on Product Innovation to a focus on Marketing Innovation, the motion and weight has transferred to marketing from product development. Once the total focus of management is directed to the marketing efforts, the product development becomes secondary, and the weight of the oblong shape is carried forward, moving towards the next stage. Should the weight remain in product development, then the marketing focus will not be able to be fully engaged, thus creating deadweight that will either pull the firm back to the Introduction stage, or render no forward motion within the market, thus retarding the advancement to the next stage of firm evolution.
Maturity means that the management focus becomes more inward looking and granular towards cost and performance, and is concerned with only incremental innovation. The evolution of management has moved from big ideas to incremental improvement - from blue ocean (Kim and Mauborgne, 2005; tinyurl.com/l7g2kzg) to Kaizen-related process improvements (tinyurl.com/bjakl) - and leaderships follows inexorably. A creative culture supports breakthrough product innovation; a supportive culture underpins the marketing moves, which first are bold and then become cautious; and productionquality focused, incremental innovation is shepherded by both quality and production culture.

Table 1 captures the evolution of the innovation profile along the lifecycle and the dominant function that generates it. The predictive nature of this model is based upon the alignment of management practices and foci during the various lifecycle stages, but the actual success of the firm's product is up to the technology and market conditions that the firm is experiencing. The periods of evolution between stages may allow two dimensions of innovation to be simultaneously managed

Table 1. The changing focus of innovation management through a firm's lifecycle

\begin{tabular}{|c|c|c|c|c|}
\hline & \multicolumn{4}{|c|}{ Lifecycle Stage } \\
\hline & Introduction & Growth & Maturity & Decline \\
\hline Management Focus & Product & Marketing & Process & Financial \\
\hline Marketing Process & & & & \\
\hline $\begin{array}{l}\text { Leadership and } \\
\text { Management Style }\end{array}$ & $\begin{array}{l}\text { Outward looking; broad } \\
\text { focus, cult of personality; } \\
\text { selling the future }\end{array}$ & $\begin{array}{l}\text { Outward looking; } \\
\text { supportive, marketing } \\
\text { focus; introduction of } \\
\text { professional/ } \\
\text { functional managers; } \\
\text { return on investment }\end{array}$ & $\begin{array}{l}\text { Inward looking; defence of } \\
\text { market share; highly } \\
\text { formal and hierarchical; } \\
\text { department- or division- } \\
\text { based; dictatorial }\end{array}$ & $\begin{array}{l}\text { Inward looking; corporate } \\
\text { value maximizing for sale } \\
\text { or liquidation; } \\
\text { disconnection from } \\
\text { workforce }\end{array}$ \\
\hline Innovation and $R \& D$ & $\begin{array}{l}\text { Large technical gains; } \\
\text { pursuit of any } \\
\text { opportunities }\end{array}$ & $\begin{array}{l}\text { Product and variant } \\
\text { development; fit to } \\
\text { existing channels; } \\
\text { reliability enhancements }\end{array}$ & $\begin{array}{l}\text { Incremental innovation in } \\
\text { production or delivery; } \\
\text { highly controlled; high } \\
\text { levels of review and } \\
\text { acceptance prior to } \\
\text { implementation }\end{array}$ & $\begin{array}{l}\text { Highly constrained; little } \\
\text { or no R\&D; potential to sell } \\
\text { intellectual property; spin- } \\
\text { off }\end{array}$ \\
\hline Corporate Culture & $\begin{array}{l}\text { Unstructured; } \\
\text { achievement-based }\end{array}$ & $\begin{array}{l}\text { Formalization of corporate } \\
\text { identity and behavioural } \\
\text { norms }\end{array}$ & $\begin{array}{l}\text { Lean or Taylorist; task- } \\
\text { based, individual- } \\
\text { performance judged }\end{array}$ & $\begin{array}{l}\text { Adversarial; rigid roles and } \\
\text { job descriptions }\end{array}$ \\
\hline
\end{tabular}




\section{Corporate Lifecycles: Modelling the Dynamics of Innovation and Its Support Infrastructure} Tamas Koplyay, Lisa Chillingworth, and Brian Mitchell

for a short period of time, but as the lifecycle continues, the dominant dimension of innovation has to take precedence over others. Should a firm not evolve their approach as they move along the lifecycle, they run the risk of atrophy or even regression within their market. As well, focusing on more than one management dimension after evolving to the next stage of the lifecycle will result in negative effects, because time and effort will be expended without moving the organization forward; a second focus will either detract from the main focus or require additional resources.

Figure 2 shows possible failure scenarios using the "egg model". Firms splitting their innovation management focus without additional resources will lose opportunities, whereas firms adding resources will then lose efficiency for labour costs. In Figure 2A, pursuing two dimensions fully may result in additional product innovation while market innovation is being pursued, but the efficiency and efficacy of incurring the additional product-development costs may demonstrate the law

A. Pursuing two innovation dimensions with additional resources

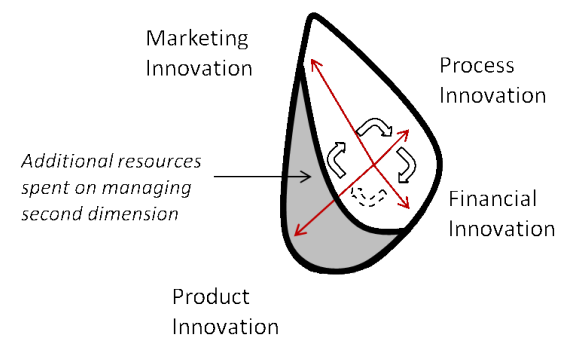

B. Pursuing two innovation dimensions without additional resources

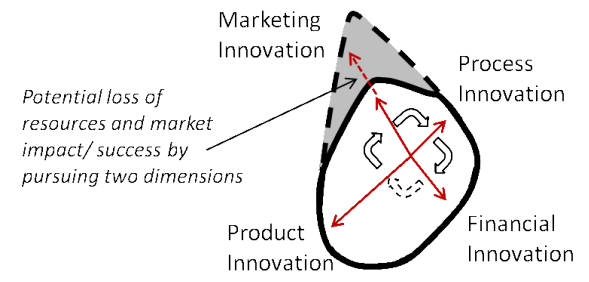

C. Pursuing the wrong dimensions of innovation

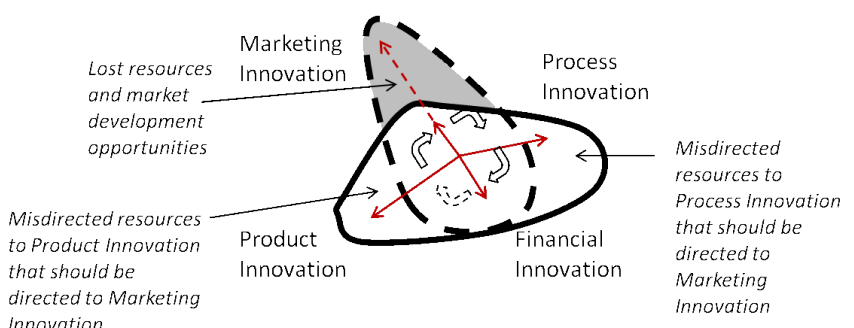

Figure 2. Possible failure scenarios when a firm focuses on two dimensions of innovation or the wrong dimension of diminishing returns, as well as requiring a reworking of marketing initiatives. Figure 2B shows the loss of Marketing Innovation effort if two dimensions are pursued without additional resources. By splitting its focus, a firm could realize proportionately less ultimate success than the percentage of effort due to inherent underfunding of the most important innovation search. Figure 2C shows the loss of Marketing Innovation and the costs of pursing the wrong innovation dimensions.

One observation of the "egg" shape is that, by allocating the resources to the proper dimension, the process will create or maintain motion to the next stage: the egg will continue to roll. The flatter the resultant shape, as shown in Exhibit 2C, the less motion it can create through natural progression, and the egg will remain stationary. Should the weight be distributed to the wrong side, as shown in Exhibit 2A, the more it will want to roll backwards and return to the previous dimension, thus regressing in the market and perhaps leading to early decline.

\section{Conclusion}

In every firm, there is either a culture that supports the innovative efforts of the firm or a culture that cannot understand or adapt to innovation due to a non-alignment of their corporate culture or leadership. As we have shown in this article, both the leadership and the culture have to align to the lifecycle stage that the firm is experiencing in order to maximize support for innovation. Innovation changes from the Introduction stage, where boundary-stretching leadership allows creative people to pursue opportunities and technical advances; Growth means formalization of behaviour and more professional management; Maturity focuses on defending market share and incremental innovation, and is usually focused on cost leadership; and Decline attempts to maximize value for closure or a rebirth. In every stage, even Decline, there can be innovation that either moves the firm forward or staves off closure. The model, as illustrated graphically, shows the strategic imperatives that firms must address in each stage of its lifecycle, and it shows how an unbalanced approach to innovation when combining culture and leadership will result in the forward motion being either slowed, or permanently retarded, to the detriment of the firm. Although the model allows for the evolution from one stage to the next, the logic supporting the model dictates that not more than one primary strategic direction, or innovation dimension, should be pursued at any one time in order to maximize the firm's ability to succeed in addressing the dynamics of innovation. 


\section{Corporate Lifecycles: Modelling the Dynamics of Innovation and Its Support Infrastructure Tamas Koplyay, Lisa Chillingworth, and Brian Mitchell}

\section{About the Authors}

Tamas Koplyay is Professor of High-Technology Strategic Management at the Université du Québec en Outaouais in Gatineau, Canada. He received Master's degrees in Systems Engineering, Applied Mathematics, and Information Theory from the State University of New York, United States; he received his MBA from the University of Ottawa, Canada; and he received his $\mathrm{PhD}$ in Systems Science from Michigan State University, United States. He has been a visiting researcher at the Harvard Law School in Public Finance. Currently, he is also the Director of Research for the Canadian Advanced Technology Alliance as part of his university commitments to the high-technology community.

Lisa Chillingworth a $\mathrm{PhD}$ candidate in Management and Business Administration at Szent István University in Budapest, Hungary. She obtained her Bachelor of Arts degree from York University in Toronto, Canada. She is a Project Management Professional (PMP) and LEED Accredited Professional (Leadership in Energy and Environmental Design) and holds her Masters degree in Project Management from the Université du Québec, Canada, for which she received the 2012 Governor General's Gold Medal for academic excellence. Ms. Chillingworth has 20 years of experience in project management and is currently the Director of Program Management and Advisory Services, North America, for an international real estate and capital facilities project management firm. Previously, Ms. Chillingworth spent a number of years as a project and management consultant, specializing in business transformation, operations, and strategic planning. She is also the Director of International Corporate Relations for the Global Academic Network, and their annual Global Management Conference, which work to bridge academia and the business community. She is also an Executive in Residence and Associate Director of Research for the Canadian Advanced Technology Alliance (CATA).
Brian Mitchell is a $\mathrm{PhD}$ candidate in Management and Business Administration at Szent István University in Budapest, Hungary. He holds a Master's degree in Project Management from the Université du Quebec, Canada, is a Project Management Professional (PMP), and LEED Accredited Professional (Leadership in Energy and Environmental Design) in the building design and construction industry. Mr. Mitchell has over 25 years of diverse experience in the delivery and management of capital projects and related work. As the National Practice Manager for a leading Canadian project management company, Mr. Mitchell was responsible for corporate research, project management best practice methodologies, and knowledge transfer across Canada. He was also a reviewer of the Project Management Institute's Construction Extension to the PMBoK Guide, Second Edition.

Citation: Koplyay, T., L. Chillingworth, and B. Mitchell. 2013. Corporate Lifecycles: Modelling the Dynamics of Innovation and Its Support Infrastructure. Technology Innovation Management Review. October 2013: 22-29.

Keywords: innovation, innovation management, market lifecycle, organizational culture, staffing, leadership, model 